\title{
Tuberização e produtividade de batata-doce em função de datas de plantio em clima subtropical
}

\author{
Lígia Erpen; Nereu Augusto Streck (*); Lilian Osmari Uhlmann; Charles Patrick de Oliveira de \\ Freitas; Jerônimo Luiz Andriolo
}

Universidade Federal de Santa Maria (UFSM), Centro de Ciências Rurais, 97105-900 Santa Maria (RS), Brasil.

(*) Autor correspondente: nstreck2@yahoo.com.br

Recebido: 22/7/2013; Aceito: 22/10/2013

\section{Resumo}

O objetivo deste trabalho foi avaliar o efeito de datas de plantio no início de tuberização (IT) e na produtividade de raízes tuberosas de batata-doce em clima subtropical. Um experimento de campo foi conduzido em Santa Maria, RS, Brasil, com quatro datas de plantio (25/8/2011; 21/11/2011; 3/1/2012 e 13/2/2012), para obter plantas crescendo em diferentes condições ambientais, principalmente de temperatura e fotoperíodo. A variedade usada foi a Princesa, na densidade de plantio de 25 mil plantas ha-1 O delineamento experimental utilizado foi o de blocos ao acaso com quatro repetições. Duas semanas após o plantio foram coletadas quatro plantas a cada dois dias para a determinação do IT. A colheita foi realizada em 15/5/2012. A duração das fases plantio a início de tuberização (PL-IT) e início de tuberização a colheita (IT-CO) foi expressa em dias do calendário civil e em soma térmica $\left({ }^{\circ} \mathrm{C}\right.$ dia). As condições de temperatura e fotoperíodo modificaram a duração da fase PL-IT em cada data de plantio, indicando que fotoperíodos curtos e temperaturas mais altas aceleram o IT. A produtividade de raízes tuberosas foi maior quando o plantio foi realizado no final do inverno (25/8/2011), em decorrência da maior duração da fase IT-CO, que coincidiu com os períodos de alta incidência de radiação solar e temperaturas favoráveis ao crescimento e desenvolvimento da batata-doce.

Palavras-chave: Ipomoea batatas, raiz tuberose, fotoperíodo, temperatura.

\section{Tuberization and yield of sweet potato as affected by planting date in a subtropical climate}

\begin{abstract}
The objective of this study was to assess the effect of planting dates on tuber initiation (TI) and yield of sweet potato in a subtropical climate. A field experiment was carried out at Santa Maria, RS, Brazil, with four planting dates (08/25/2011; 11/21/2011; 01/03/2012 and 02/13/2012), to obtain plants growing in different environmental conditions, especially temperature and photoperiod. The variety Princesa was planted at a density of 25.000 plants ha ${ }^{-1}$. The experiment was a complete randomized block design with four replications. Two weeks after planting four plants were collected every two days for determining the TI. Harvesting of all planting dates took place at 05/15/2012. The duration of phases between planting to tuber initiation (PL-TI) and tuber initiation to harvest ( $\mathrm{TI}-\mathrm{HA}$ ) was expressed in calendar days and thermal time $\left({ }^{\circ} \mathrm{C}\right.$ day). The conditions of temperature and photoperiod modified PL-TI duration in each planting date, indicating that short photoperiods and higher temperatures accelerate TI. The potato yield was higher when planting was done in late winter (08/25/2011) due to increased TI-HA duration, which coincided with periods of high solar radiation and temperatures favorable to the growth and development of sweet potato.
\end{abstract}

Key words: Ipomoea batatas, storage root, photoperiod, temperature.

\section{INTRODUÇÃO}

Determina-se a época de plantio da batata-doce em função de elementos climáticos como temperatura do ar, fotoperíodo e radiação solar, os quais têm influência sobre o crescimento, desenvolvimento e produtividade de raízes tuberosas (Medeiros et al., 1990; Villordon et al., 2010). Segundo Queiroga et al. (2007), o ciclo de desenvolvimento da batata-doce pode ser dividido em três fases: uma fase inicial em que ocorre crescimento das raízes adventícias, uma fase intermediária em que ocorre o início de tuberizaçáo das raízes e a fase final, caracterizada pelo acúmulo de fotoassimilados nas raízes tuberosas. Início de tuberização (IT) precoce, alta taxa de acumulação de amido e longo período de acúmulo de reservas nas raízes aumentam a produtividade (Somasundaram e Mithra, 2008).

O IT caracteriza-se pelo aumento do diâmetro das raízes adventícias (Medeiros et al., 1990). A temperatura é descrita como uma das principais variáveis que determinam 
a formação de raízes tuberosas, sendo essa formação sensível tanto a baixas como a altas temperaturas. Temperaturas elevadas atrasam ou impedem o IT devido à lignificação das raízes adventícias (VILLORDon et al., 2009). A temperatura ideal para o crescimento das raízes está em torno de $25^{\circ} \mathrm{C}$, ocorrendo paralização do crescimento em temperaturas abaixo de $15^{\circ} \mathrm{C}$ e acima de $35^{\circ} \mathrm{C}$ (Ravi et al., 2009; SPEnCE e Humphries, 1972; Villavicencio et al., 2007).

Outra variável do ambiente que determina o IT é o fotoperíodo (MedeIros et al., 1990), embora haja controvérsia na literatura sobre seu efeito. Somasundaram e Mithra (2008) afirmam que o desenvolvimento das raízes é estimulado por fotoperíodos curtos (13 horas). McDavid e Alamu (1980) verificaram que o aumento do fotoperíodo de oito para 18 horas reduziu a produção de raízes, que foi maior em plantas expostas a fotoperíodos de 11,5 a 12,5 horas. Em contraste, Mortley et al. (2009) afirmam que fotoperíodos longos (18 horas) promoveram maior produtividade que fotoperíodos curtos (nove horas), assim como Bonsi et al. (1994), que relatam maior produtividade em fotoperíodo de 24 horas que em fotoperíodo de 12 horas. Segundo RAvi et al. (2009), ainda não está esclarecido o papel do fotoperíodo na dinâmica da indução e crescimento das raízes tuberosas da batata-doce.

A radiação solar é outro elemento meteorológico importante no processo de crescimento das raízes de batatadoce (VILLORDON et al., 2010). Após o IT, a produtividade depende da capacidade de a parte aérea produzir assimilados e translocá-los para as raízes (Somasundaram e Mithra, 2008). Consequentemente, níveis elevados de radiação solar afetam positivamente a produtividade de raízes, já que essa variável é a fonte de energia para a fotossíntese. Durante o período de crescimento das raízes tuberosas, níveis elevados de radiação solar combinados com temperaturas adequadas contribuem para maior produção de matéria seca total e, consequentemente, para o rendimento das raízes tuberosas (Conceição et al., 2004).

As raízes crescem continuamente após o IT, não havendo um momento específico de colheita, que pode iniciar-se aos 90 dias mas em geral ocorre entre 120 e 150 dias após o plantio, dependendo do ciclo da cultivar e das condiçóes ambientais de cultivo (Resende et al., 2000). Assim, a época de plantio tem um papel importante na produtividade de batata-doce. No Rio Grande do Sul (RS), que apresenta clima subtropical, o período de crescimento da batata-doce é interrompido no inverno devido às baixas temperaturas e à ocorrência de geadas, devendo o plantio ser realizado após essa estação.

Não foram encontrados resultados na literatura indicando o efeito da época de plantio da batata-doce no $\mathrm{RS}$ visando maior produtividade e sua relaçáo com elementos meteorológicos (temperatura do ar, fotoperíodo e radiaçáo solar) durante o período de crescimento da cultura. O objetivo deste trabalho foi avaliar o efeito de datas de plantio no IT e na produtividade de raízes tuberosas de batata-doce em ambiente subtropical.

\section{MATERIAL E MÉTODOS}

Um experimento de campo foi conduzido em Santa Maria, RS ( $29^{\circ} 43^{\prime} \mathrm{S}, 53^{\circ} 43^{\prime} \mathrm{W}$ e altitude de $\left.95 \mathrm{~m}\right)$. O solo do local é uma transição entre a Unidade de Mapeamento São Pedro (Argissolo Vermelho distrófico arênico) e a Unidade de Mapeamento Santa Maria (Alissolo Hipocrômico argilúvico típico) (Streck et al., 2008). Segundo a classificação de Köppen, o clima é do tipo Cfa, subtropical úmido com veróes quentes e sem estação seca definida.

A cultivar de batata-doce utilizada foi a Princesa, da Embrapa Hortaliças, com boa adaptabilidade nas diferentes regiōes brasileiras. É considerada uma cultivar tardia, devendo ser colhida a partir dos 120-150 dias. Possui produtividade potencial de 25 a $30 \mathrm{~kg} \mathrm{ha}^{-1}$, crescimento rápido e grande vigor vegetativo, o que possibilita o uso da parte aérea na alimentação animal (SiLva e Lopes, 1995).

As mudas utilizadas no plantio foram produzidas em bandejas de 128 células com substrato comercial, através do enraizamento de hastes com três a quatro nós, coletadas de plantas matrizes. O preparo do solo foi convencional, com araçáo e gradagem e construção de camalhóes de 30 $\mathrm{cm}$ de altura. A adubação foi aplicada no camalhão antes do plantio, de acordo com a análise química do solo e as recomendaçóes técnicas para a cultura (Sociedade Brasileira de Ciência do Solo, 2004). O plantio foi realizado quando as mudas tinham seis a oito folhas, no espaçamento de $1,0 \mathrm{~m}$ (entre camalhóes) $\times 0,4 \mathrm{~m}$ (entre plantas), o que equivale a uma densidade de 25 mil plantas $\mathrm{ha}^{-1}$. Na primeira semana após o transplante foram realizadas irrigaçóes diárias para facilitar o pegamento das mudas. Após esse período foram realizadas irrigaçóes suplementares somente após longos períodos sem precipitação ( 10 a 15 dias), de modo que não houve déficit hídrico que comprometesse o crescimento das raízes tuberosas. O controle de plantas daninhas foi manual, por meio de capinas.

O delineamento experimental foi blocos ao acaso com quatro repetiçóes. Cada parcela foi constituída de cinco camalhóes de $4 \mathrm{~m}$ de comprimento com dez plantas por camalhão (50 plantas por parcela). Em uma área adjacente foram cultivadas duas linhas com plantas para determinaçáo do início de tuberizaçáo (IT). O plantio foi realizado em quatro datas: 25/8/2011, 21/11/2011, 3/1/2012 e $13 / 2 / 2012$. Essas datas foram definidas considerando-se a época mais indicada para plantio na região, que ocorre do final do inverno ao final da primavera, e também para obter plantas crescendo em diferentes condiçóes ambientais, principalmente de temperatura e fotoperíodo, a fim de determinar a influência dessas variáveis sobre o IT e o crescimento das raízes tuberosas. 
Para determinar o IT, quatro plantas foram coletadas a cada dois dias na área adjacente ao experimento e o diâmetro de suas raízes foi medido com paquímetro. A data do IT foi considerada quando $50 \%$ das plantas amostradas apresentaram pelo menos uma raiz tuberosa com $5 \mathrm{~mm}$ de diâmetro (VIllordon et al., 2009). Nesse dia foi contado o número de nós (NN no IT) das plantas amostradas.

A colheita em todas as parcelas foi realizada em 15/5/2012, antes do início do inverno e da ocorrência de geadas, variando de 92 dias (última época) a 264 dias (primeira época de plantio) após o plantio. Como não há um critério sobre ponto de colheita da raiz da batata-doce (quanto mais tempo a raiz ficar crescendo no campo, maior seu tamanho final e maior o número de raízes por planta e, portanto, maior a produtividade) optou-se por colher todas as parcelas no mesmo dia. Foram colhidas oito plantas do camalhão central de cada parcela e determinada a produtividade de raízes em massa fresca. As raízes foram classificadas em comerciais e não comerciais (raízes abaixo de $100 \mathrm{~g}$ ) (Resende et al., 2000). A parte aérea de quatro plantas e dez raízes tuberosas representativas da parcela foram colocadas em estufa de ventilação forçada a $60^{\circ} \mathrm{C}$ até massa constante, para determinação da massa seca e posterior cálculo da proporção de massa seca de raízes em cada parcela. A produtividade em $\mathrm{kg} \mathrm{ha}^{-1}$ foi calculada extrapolando-se a área de parcela útil para um hectare.

A duração das fases do plantio ao início de tuberizaçáo (PL-IT) e do início de tuberização à colheita (IT-CO) foi expressa em dias do calendário civil e em soma térmica $\left({ }^{\circ} \mathrm{C}\right.$ dia $)$. A soma térmica diária $\left(\mathrm{STd},{ }^{\circ} \mathrm{C}\right.$ dia $)$ foi calculada segundo ARNOLD (1960):

$\mathrm{STd}=(\mathrm{T}-\mathrm{Tb})$, quando $\mathrm{Tb}<\mathrm{T} \leq \mathrm{Tot}$

$\mathrm{STd}=\frac{(\mathrm{Tot}-\mathrm{Tb}) \cdot(\mathrm{TB}-\mathrm{T})}{\mathrm{TB}-\mathrm{Tot}}$, quando $\mathrm{Tot}<\mathrm{T} \leq \mathrm{TB}$

em que Tb, Tot e TB são as temperaturas cardinais basal inferior, ótima e basal superior, respectivamente, para o crescimento das raízes, e TM é a temperatura média diária do ar $\left({ }^{\circ} \mathrm{C}\right)$. Utilizou-se $\mathrm{Tb}=15^{\circ} \mathrm{C}$; Tot $=25^{\circ} \mathrm{C}$; e Tmax $=35^{\circ} \mathrm{C}$ (Ravi et al., 2009; Spence e Humphries, 1972; VillaVicencio et al., 2007).

A soma térmica acumulada $\left(\mathrm{ST}\right.$,,${ }^{\circ} \mathrm{C}$ dia $)$ em cada fase foi calculada acumulando-se os valores de STd (ArNold, 1960):

$\mathrm{STa}=\sum \mathrm{STd}$

Os dados diários de temperatura mínima (TN) e máxima (TX) do ar e radiação solar global incidente foram coletados na Estação Climatológica Principal do $8^{\circ}$ Distrito de Meteorologia do Instituto Nacional de Meteorologia (Disme/Inmet), a 100 metros da área experimental. A TM diária foi calculada pela média aritmética de TN e TX. O fotoperíodo diário (considerando-se a duração do crepúsculo civil de $6^{\circ}$ abaixo do plano do horizonte) foi calculado com o algoritmo de KeIsLing (1982).

Os dados de massa fresca e seca de raízes comerciais e não comerciais e massa seca de parte aérea foram submetidos à análise de variância e as médias foram comparadas pelo teste de Tukey a 5\% de significância. Os dados de massa fresca e seca de raízes tuberosas foram ainda submetidos à análise de correlação de Pearson com a duração das fases PL-IT, IT-CO, radiação solar incidente durante a fase IT-CO, NN no IT e massa seca da parte aérea, com o objetivo de identificar caracteres determinantes da produtividade de raízes tuberosas de batata-doce. $\mathrm{Na}$ análise de correlação de Pearson utilizaram-se 16 elementos (quatro épocas x quatro repetiçóes, $n=16$ ). Para a duração das fases PL-IT e IT-CO não foi possível realizar análise de variância, pois em função da metodologia usada, tanto para o IT como para o dia da colheita há apenas um valor por época (o IT foi quando $50 \%$ das plantas amostradas estavam com o critério de IT acima descrito e o dia da colheita foi o mesmo para todas as épocas, conforme descrito acima).

\section{RESULTADOS E DISCUSSÃO}

Ao longo da estação de crescimento, a disponibilidade de radiação solar e o fotoperíodo foram crescentes de agosto a dezembro e decrescentes de janeiro a maio (Figura 1), com mínimo de $10,2 \mathrm{MJ} \mathrm{m}^{-2} \operatorname{dia}^{-1}$ e 11,5 horas para a radiação solar e o fotoperíodo, respectivamente, nos meses de agosto de 2011 e maio de 2012, e máximo de $20,3 \mathrm{MJ} \mathrm{m}^{-2} \mathrm{dia}^{-1}$ e 14,9 horas para a radiação solar e o fotoperíodo, respectivamente, no mês de dezembro de 2011. A temperatura do ar também foi crescente de agosto a fevereiro e decrescente a partir de fevereiro até maio, com mínimo de $10,9^{\circ} \mathrm{C}$ em agosto de 2011 e máximo de $33,1^{\circ} \mathrm{C}$ em fevereiro/2012 (Figura 1).

A duração, em dias, da fase PL-IT variou entre as datas de plantio (Figura 2a), sendo maior na primeira data (70 dias) que nas outras três datas $(58,55$ e 53 dias, na segunda, terceira e quarta data, respectivamente). A maior duração dessa fase na primeira data de plantio, que ocorreu em final de agosto ao início de novembro, pode ser explicada pela exposição das plantas a temperaturas mais baixas, com as médias mensais variando de $15^{\circ} \mathrm{C}$ a $20^{\circ} \mathrm{C}$ (Figura 1a), o que reduziu o acúmulo térmico diário e assim mais dias foram necessários para se atingir o IT. Nas outras datas, essa mesma fase ocorreu entre os meses de dezembro a março, quando as médias mensais de temperatura do ar variaram de $24^{\circ} \mathrm{C}$ a $27^{\circ} \mathrm{C}$, próximo à temperatura ótima para o crescimento das raízes $\left(25^{\circ} \mathrm{C}\right)$ (Ravi et al., 2009). Medeiros et al. (1990) relatam que o IT para as cultivares Princesa e Coquinho ocorreu aos 45 e 30 dias após o plantio, realizado em 30/11 e 3/1 na regiáo de Brasília, DF, onde a temperatura do ar é alta e o fotoperíodo é mais curto do que em Santa Maria, $\mathrm{RS}$, nos meses de verão. 

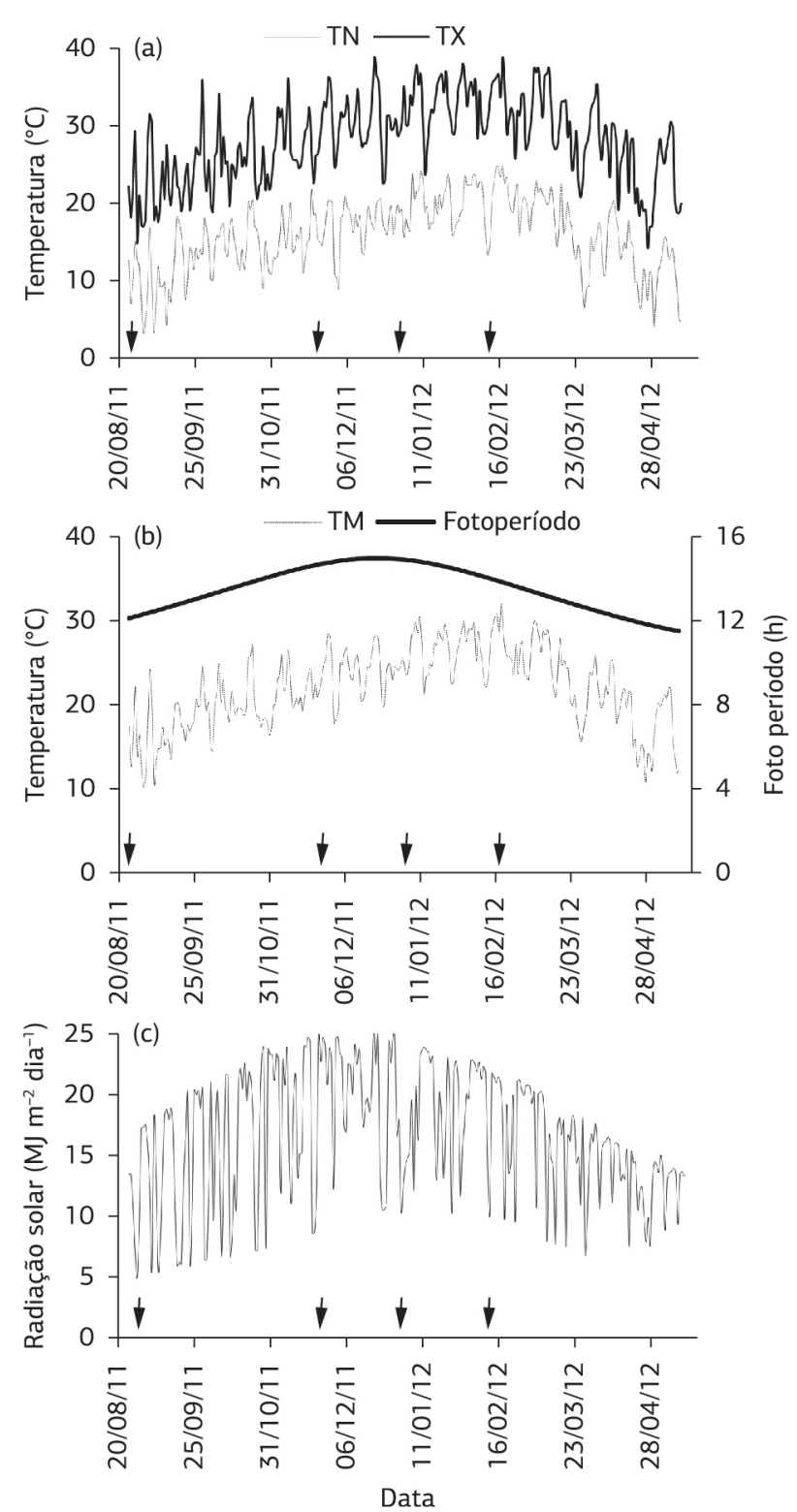

Figura 1. Temperaturas mínimas (TN) e máximas (TX) diárias do ar (a); temperatura média diária do ar (TM) e fotoperíodo (b); e densidade de fluxo de radiação solar global incidente (c) durante o período de cultivo da batata-doce com quatro datas de plantio (25/8/2011, 21/11/2011,3/1/2012 e13/2/2012), indicadas pelas setas

Quando a duração da fase PL-IT foi expressa em ${ }^{\circ} \mathrm{C}$ dia, também houve diferença entre as datas de plantio, mas de forma oposta à tendência que ocorreu entre as datas de plantio no período PL-IT expresso em dias do calendário civil (Figura 2b). A primeira data de plantio apresentou menor duraçáo $\left(252^{\circ} \mathrm{C}\right.$ dia), seguida pela quarta $\left(364^{\circ} \mathrm{C} \mathrm{dia}\right)$, terceira $\left(404^{\circ} \mathrm{C} \mathrm{dia}\right)$ e segunda $\left(456^{\circ} \mathrm{C}\right.$ dia $)$ data de plantio. A hipótese para explicar esse resultado é o fotoperíodo médio do período entre o plantio e o IT, que variou de 13,1 a 14,9 nas quatro datas e apresentou relação linear positiva com a $\mathrm{STa}\left(\mathrm{R}^{2}=0,76\right)$ (Figura 3 ), ou seja, à medida que aumentou o fotoperíodo, maior foi a soma térmica necessária para
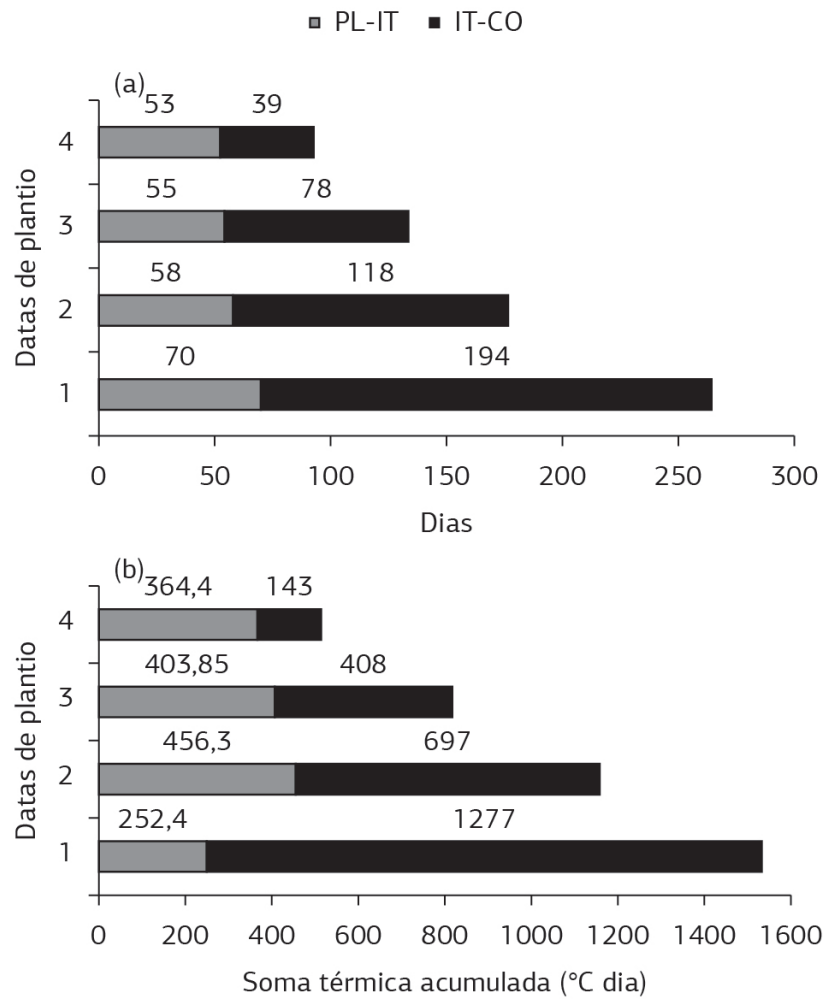

Figura 2. Duração da fase plantio-início da tuberização (PL-IT) e início da tuberização-colheita (IT-CO) em dias (a) e em ${ }^{\circ} \mathrm{C}$ dia (b) nas quatro datas de plantio (1: 25/8/2011; 2: 21/11/2011; 3: 3/1/2012; e 4: 13/2/2012) de batata-doce cultivar Princesa

atingir o IT. Em condiçôes de maior soma térmica, maior é o NN nessa fase, pois a emissão de nós em batata-doce é determinada pela temperatura do ar (SOMASUNDARAM e Mithra, 2008), o que se confirma pela relação quadrática ajustada entre fotoperíodo e NN no IT (Figura 3). Esses resultados confirmam o que foi relatado por MCDAvid e Alamu (1980), Onwueme e Charles (1994); Silva e Lopes (1995), de que fotoperíodos mais curtos favorecem a formação de raízes tuberosas na batata-doce e contrapóem-se aos resultados de Bonsi et al. (1994) e MortLey et al. (2009), que encontraram maior produção de raízes sob fotoperíodos longos, de 24 e 18 horas, respectivamente.

A produtividade comercial $\left(\mathrm{kg} \mathrm{ha}^{-1}\right)$ de raízes tuberosas na primeira data de plantio $\left(21.500 \mathrm{~kg} \mathrm{ha}^{-1}\right)$ foi superior àquelas obtidas na segunda $\left(9.900 \mathrm{~kg} \mathrm{ha}^{-1}\right)$ e terceira $\left(7.100 \mathrm{~kg} \mathrm{ha}^{-1}\right)$, as quais não diferiram significativamente entre si (Tabela 1 ). A quarta data de plantio foi inferior às outras datas de plantio e produziu apenas raízes não comerciais (Tabela 1). O coeficiente de variaçáo (CV) foi elevado (29\%) para as variáveis de produtividade comercial e não comercial, o que é comum para culturas tuberosas, pois há grande variabilidade na formação de raízes tuberosas por planta. Mesmo assim, é notável a diferença entre épocas de plantio. A produtividade total (comercial + não comercial) foi similar à produtividade comercial (Tabela 1). Esses resultados podem ser explicados pela duração do período IT-CO, radiaçáo solar incidente 
nesse período e pela produção de massa seca da parte aérea, que tiveram correlação positiva e elevada $(r=0,99)$ com a produtividade de raízes comerciais (Tabela 2).

A produção da raiz tuberosa é uma função da capacidade de dreno e do potencial da fonte (ConCeIÇấo et al., 2004). Nesse sentido, a área foliar (fonte) é um fator determinante da produção, pois sua redução implica menor absorção de energia radiante e fotossíntese menos intensa, reduzindo-se, assim, a produção de biomassa (Oliveira et al., 2010). A produtividade está relacionada à manutenção da área fotossintetizante durante o período de crescimento da parte de interesse comercial (LeNis et al., 2006). Esse autor cita que o aumento da longevidade e retenção de folhas de plantas de mandioca apresentou correlação positiva com a produtividade de raízes dessa cultura. $\mathrm{O}$ mesmo é relatado por SagriLo et al. (2002), em que o bom crescimento da estrutura vegetativa das plantas de mandioca levou a maior acúmulo de fotoassimilados nas raízes tuberosas, aumentando a sua produtividade. Cecílio Filho e MAY (2002) também relatam que o aumento da massa seca de parte aérea do rabanete levou a maior produção de massa seca de raízes.

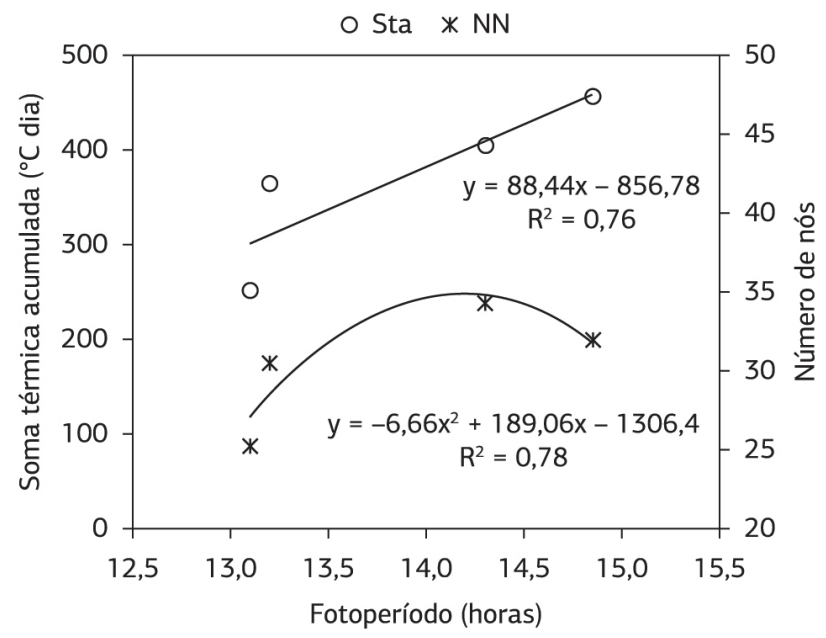

Figura 3. Relação entre a duração da fase PL-IT em ${ }^{\circ} \mathrm{C}$ dia e o número de nós da haste principal no início de tuberizaçáo com o fotoperíodo médio do período nas quatro datas de plantio de batatadoce cultivar Princesa
A batata-doce é uma cultura perene, de tuberização contínua sob condiçôes favoráveis, de modo que a maior duração do período IT-CO permite maior tempo para a acumulação de fotoassimilados nas raízes. Em trabalhos avaliando a época de colheita dessa cultura, RoESLER et al. (2008) obtiveram produtividade de $4.250 \mathrm{~kg} \mathrm{ha}^{-1}$ e $9.140 \mathrm{~kg} \mathrm{ha}^{-1}$ ao efetuar a colheita aos 115 DAP e aos 183 DAP, respectivamente, em Marechal Cândido Rondon, PR. Queiroga et al. (2007) também obtiveram produtividade de raízes comerciais de $17.700 \mathrm{~kg} \mathrm{ha}^{-1}, 11.000 \mathrm{~kg} \mathrm{ha}^{-1}$ e $9.100 \mathrm{~kg} \mathrm{ha}^{-1}$ em colheitas realizadas aos $150 \mathrm{DAP}$, 130 DAP e 105 DAP, respectivamente, em Mossoró, RN. Comparando-se a produtividade da cultivar Princesa aos 150 DAP e aos 200 DAP em Porteirinha, MG, Resende et al. (2000) obtiveram aumento na produtividade da ordem de $116 \%$ em função de maior período de permanência da cultura no campo.

$\mathrm{O}$ atraso na colheita nem sempre garante incremento em produtividade, o resultado depende das condiçôes meteorológicas do período, como radiação solar, elemento que afeta diretamente a produtividade da batata-doce (CoNCEIÇão et al., 2004; Villordon et al., 2010). No presente estudo, os meses de novembro a fevereiro apresentaram valores mais altos de radiação solar incidente (Figura 1c) e coincidiram com o período de acumulaçáo de amido da primeira data de plantio, que iniciou-se em 3/11. Com maior disponibilidade de radiação solar, as plantas dessa data de plantio foram capazes de produzir maior massa seca total, tanto da parte aérea como das raízes tuberosas (Tabela 1). As plantas da segunda e da terceira data de plantio iniciaram a fase de acumulaçáo de amido em 18/1 e 27/2, respectivamente, quando a radiação solar incidente estava em declínio (Figura 1c). As plantas da quarta data de plantio iniciaram a fase de acumulaçáo de amido em $6 / 4$, quando os níveis da radiação solar incidente estavam ainda menores (Figura 1c), o que, aliado ao curto período de acumulação de amido (39 dias), levou a baixa produtividade de raízes. Nesse caso, mesmo que a colheita fosse adiada para além do dia 15 de maio, aumentando assim o período para acumulação de amido nas raízes, a reduçáo da temperatura e da radiação solar incidente a partir dessa data não garantiriam incrementos em produtividade. Os plantios tardios de batata-doce em regiōes subtropicais

Tabela 1. Produtividade comercial, não comercial e total (comercial + não comercial) de raízes tuberosas em massa fresca (MF) e massa seca (MS) e de massa seca de parte aérea (MSPA) de batata-doce cultivar Princesa conforme quatro datas de plantio

\begin{tabular}{|c|c|c|c|c|c|c|c|}
\hline \multirow{3}{*}{$\begin{array}{l}\text { Data de } \\
\text { plantio }\end{array}$} & \multicolumn{6}{|c|}{ Produtividade $\left(\mathrm{kg} \mathrm{ha}^{-1}\right)$} & \multirow{3}{*}{$\begin{array}{c}\text { MSPA } \\
\left(\mathrm{kg} \mathrm{ha}^{-1}\right)\end{array}$} \\
\hline & \multicolumn{2}{|c|}{ Comercial } & \multicolumn{2}{|c|}{ Não comercial } & \multicolumn{2}{|c|}{ Total } & \\
\hline & MF & MS & MF & MS & MF & MS & \\
\hline 25/8/2011 & $21,500 a^{*}$ & $7,600 a$ & $3,700 a$ & $1,300 a$ & $25,200 a$ & $8,900 a$ & $5,400 a$ \\
\hline $21 / 11 / 2011$ & $9,900 b$ & $3,300 b$ & $3,100 a$ & $1,100 a$ & $13,000 b$ & $4,400 b$ & 4,200ab \\
\hline $3 / 1 / 2012$ & $7,100 b$ & $2,100 b c$ & $3,800 a$ & $1,200 a$ & $10,900 b$ & $3,300 b$ & $3,600 b$ \\
\hline $13 / 2 / 2012$ & Oc & Oc & $1,000 b$ & $0,300 b$ & $1,000 c$ & $0,300 c$ & $3,100 b$ \\
\hline CV (\%) & \multicolumn{2}{|c|}{29} & \multicolumn{2}{|c|}{29} & \multicolumn{2}{|c|}{26} & 15 \\
\hline
\end{tabular}

* Médias não seguidas pela mesma letra na vertical diferem pelo teste de Tukey a $5 \%$ de probabilidade 
Tabela 2. Coeficientes de correlação de Pearson entre os caracteres produtividade de raízes tuberosas em massa fresca (MF) e massa seca (MS) com a duração, em ${ }^{\circ} \mathrm{C}$ dia, das fases plantio-início de tuberização (PL-IT) e início de tuberização-colheita (IT-CO), radiação solar global incidente (RS) durante o IT-CO, número de nós na haste principal no início de tuberização (NN IT) e massa seca parte aérea (MSPA) de batata-doce cultivar Princesa

\begin{tabular}{|c|c|c|}
\hline Variáveis & $\begin{array}{c}\text { MF } \\
\left(\mathrm{kg} \mathrm{ha}^{-1}\right)\end{array}$ & $\begin{array}{c}\text { MS } \\
\left(\mathrm{kg} \mathrm{ha}^{-1}\right)\end{array}$ \\
\hline PL- IT ( ${ }^{\circ} \mathrm{C}$ dia $)$ & $-0,61 \mathrm{~ns}$ & $-0,63 n s$ \\
\hline IT-CO $\left({ }^{\circ} \mathrm{C}\right.$ dia $)$ & $0,99^{* *}$ & $1,00^{* *}$ \\
\hline $\mathrm{RS}\left(\mathrm{MJ} \mathrm{m}^{2} \mathrm{dia}^{-1}\right.$ ) & $0,99^{* *}$ & $0,99^{* *}$ \\
\hline NN IT & $-0,76 n s$ & $-0,79 n s$ \\
\hline MSPA (kg ha-1) & $0,99 * *$ & $0,99^{* *}$ \\
\hline
\end{tabular}

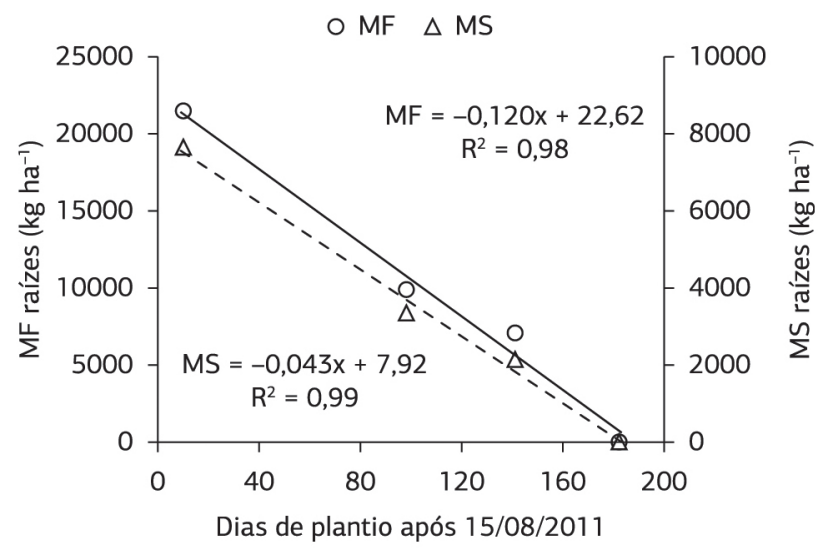

Figura 4. Produtividade de raízes tuberosas comerciais em massa fresca (MF) e massa seca (MS) em função da data de plantio (dias após 15/8/2011) para batata-doce cultivar Princesa

como o Rio Grande do Sul podem ter produtividade elevada de raízes apenas no segundo ciclo de crescimento, já que as temperaturas invernais causam a morte da parte aérea da planta, como aconteceu com as plantas da bordadura nesse experimento após uma geada ocorrida nos dias 7 e 8 de junho de 2012. Segundo Andriolo et al. (1998), a disponibilidade de radiação solar é a principal variável determinante do rendimento das plantas cultivadas fora das épocas preferenciais, desde que a temperatura não alcance níveis letais.

O efeito de reduçáo na produtividade com o atraso na data de plantio da batata-doce é melhor descrito pela relação apresentada na Figura 4. Para cada dia de atraso no plantio, houve redução de $120 \mathrm{~g}$ de matéria fresca e de $43 \mathrm{~g}$ de matéria seca de raízes tuberosas. Essa é uma redução grande e uma informação prática importante para agricultores e extensionistas maximizarem a produtividade de raízes tuberosas de batata-doce em regiōes subtropicais. A redução linear indica que quanto maior o atraso no plantio maior será a redução na produtividade de raízes dessa cultivar na região de Santa Maria, situada na Depressão Central do Rio
Grande do Sul. Entretanto, a antecipação do plantio pode ser dificultada pela disponibilidade de mudas, visto que, no inverno, o crescimento das plantas matrizes é lento ou não ocorre. Nesse caso, as mudas devem ser produzidas a partir de plantas matrizes cultivadas em ambiente protegido, para evitar danos causados pelo frio.

Os resultados deste trabalho confirmam o efeito do fotoperíodo sobre a formação de raízes tuberosas de batata-doce, o qual é determinante do ciclo de desenvolvimento da planta por influir na duração do período PL-IT. Em regiấo subtropical, quando o plantio é realizado logo após o fim do inverno, ocorrerá menor duração dessa fase devido à exposição das plantas a fotoperíodos mais curtos. Isso determina a antecipação e o aumento do período de acumulação de reservas nas raízes, que coincidirá com os períodos de maior incidência de radiação solar e de temperaturas adequadas ao crescimento e desenvolvimento da planta, contribuindo assim para aumentar a produtividade de raízes.

\section{CONCLUSÕES}

O início de tuberização da batata-doce varia com a data de plantio, indicando que fotoperíodos curtos aceleram sua ocorrência. Em clima subtropical, a produtividade é maior quando o plantio é realizado no final do inverno, em decorrência da maior duração da fase IT-CO, que coincide com os períodos de alta incidência de radiação solar e de temperaturas favoráveis ao crescimento e desenvolvimento da batata-doce.

\section{REFERÊNCIAS}

ANDRIOLO, J.L.; DALL ROSS, T.; WITTER, M. Growth, development and dry matter distribution of a tomato crop as affected by environment. Journal of Horticultural Science and Biotechnology, v.73, p.125-130, 1998.

ARNOLD, C.Y. Maximum-minimum temperatures as a basis for computing heat units. Proceedings of the American Society for Horticultural Science, v.76, p.682-692, 1960.

BONSI, C.K.; MORTLEY, D.G.; LORETAN, P.A.; HILL, W.A. Temperature and light effects of sweet potatoes grown hydroponically. Acta Horticulturae, n.361, p.527-529, 1994.

CECÍlLIO FILHO, A.B.; MAY, A. Produtividade das culturas de alface e rabanete em função da época de estabelecimento do consórcio. Horticultura Brasileira, v.20, p.501-504, 2002. http:// dx.doi.org/10.1590/S0102-05362002000300021

CONCEIÇÃO, M.K.; LOPES, N.F.; FORTES, G.R.L. Partição de matéria seca entre órgão de batata-doce (Ipomoea batatas (L.) Lam), cultivares Abóbora e Da Costa. Revista Brasileira de Agrociências, v.10, p.313-316, 2004. 
KEISLING, T.C. Calculation of the length of the day. Agronomy Journal, v.74, p.758-759, 1982. http://dx.doi.org/10.2134/agronj1 $982.00021962007400040036 x$

LENIS, J.I.; CALLE, F.; JARAMILLO, G.; PEREZ, J.C.; CEBALLOS, H.; COCK, J.H. Leaf retention and cassava productivity. Field Crops Research, v.95, p.126-134, 2006. http://dx.doi.org/10.1016/j. fcr.2005.02.007

McDAVID, C.R.; ALAMU, S. Effect of day length on the growth and development of whole plants and rooted leaves of sweet potato (Ipomoea batatas). Journal of Tropical Agriculture, v.57, p.113-119, 1980.

MEDEIROS, J.G.; PEREIRA, W.; MIRANDA, J.E.C.A. Análise de crescimento em duas cultivares de batata-doce (Ipomoea batatas (L.) Lam). Revista Brasileira de Fisiologia Vegetal, v.2, p.23-29, 1990.

MORTLEY, D.G.; BURRELL, S.; BONSI, C.K.; HILL, W.A.; MORRIS, C.E. Influence of daily light period and irradiance on yield and leaf elemental concentration of hydroponically grown sweet potato. HortScience, v.44, p.1491-1493, 2009.

OLIVEIRA, S.P.; VIANA, A.E.S.V.; MATSUMOTO, S.N.; JÚNIO, N.S.C.; SÃO JOSÉ, T.S.A.R. Efeito da poda e de épocas de colheita sobre características agronômicas da mandioca. Acta Scientiarum Agronomy, v.32, p.99-108, 2010.

ONWUEME, I.C.; CHARLES, W.B. Tropical root and tuber crops: production, perspectives and future prospects. Rome: FAO, 1994. 115p.

QUEIROGA, R.C.F.; SANTOS, M.A.; MENEZES, M.A.; VIEIRA, C.P.G.; SILVA, M.C. Fisiologia e produção de cultivares de batata-doce em função da época de colheita. Horticultura Brasileira, v.25, p.371374, 2007. http://dx.doi.org/10.1590/S0102-05362007000300010

RAVI, V.; NASKAR, S.K.; MAKESHKUMAR, T.; BABU, B.; KRISHNAN, B.S.P. Molecular physiology of storage root formation and development in sweet potato (Ipomoea batatas (L.) Lam.). Journal of Root Crops, v.35, p.1-27, 2009.

RESENDE, G. M. Características produtivas de cultivares de batatadoce em duas épocas de colheita, em Porteirinha - MG. Horticultura Brasileira, v.18, p.68-71, 2000. http://dx.doi.org/10.1590/S010205362000000100016

ROESLER, P.V.S.O.; GOMES, S.D.; MORO, E.; KUMMER, A.C.B.; CEREDA, M.P. Produção e qualidade de raiz tuberosa de cultivares de batata-doce no oeste do Paraná. Acta Scientiarum Agronomy, v.30, p.117-122, 2008.
SAGRILO, E.; VIDIGAL-FILHO, P.S.; PEQUENO, M.G.; SCAPIM, C.A.; GONÇALVES-VIDIGAL, M.C.; MAIA, R.R.; KVITSCHAL, M.V. Efeito da época de colheita no crescimento vegetativo, na produtividade e na qualidade de raízes de três cultivares de mandioca. Bragantia, v.61, p.115-125, 2002. http://dx.doi.org/10.1590/S000687052002000200005

SILVA, J.B.C.; LOPES, C.A. Cultivo de batata- doce [Ipomoea batatas (L.) Lam.]. Brasília: EMBRAPA-CNPH, 1995. 18p. (Instruçôes Técnicas - CNPH,7).

SOCIEDADE BRASILEIRA DE CIÊNCIA DO SOLO. Manual de adubaçáo e de calagem para os Estados do Rio Grande do Sul e Santa Catarina. 10. ed. Porto Alegre: Sociedade Brasileira de Ciência do Solo, 2004. 400p.

SOMASUNDARAM, K.; MITHRA, V.S. Madhuram: A simulation model for sweet potato growth. World Journal of Agricultural Sciences, v.4, p.241-254, 2008.

SPENCE, J.A.; HUMPHRIES, E.C. Effects of moisture supply, temperature and growth regulators on photosynthesis of isolated root leaves of sweet potato Ipomoea batatas. Annals of Botany, v.36, p.115-121, 1972.

STRECK, E.V.; KAMPF, N.; DALMOLIN, R.S.D.; KLAMT, E.; NASCIMENTO, P.C.; SCHNEIDER, P.; GIASSON, E.; PINTO, L.F.S. Solos do Rio Grande do Sul. Porto Alegre: EMATER/RS; UFRGS, 2008. 126 p.

VILLAVICENCIO, L.E.; BLANKENSHIP, S.M.; YENCHO, G.C.; THOMAS, J.F.; RAPER, C.D. Temperature effect on skin adhesion, cell wall enzyme activity, lignin content, anthocyanins, growth parameters, and periderm histochemistry of sweet potato. Journal of the American Society for Horticultural Science, v.132, p.729-738, 2007.

VILLORDON, A.; LABONTE, D.R.; FIRON, N. Development of a simple thermal time method for describing the onset of morphoanatomical features related to sweet potato storage root formation. Scientia Horticulturae, v.121, p.374-377, 2009. http://dx.doi. org/10.1016/j.scienta.2009.02.013

VILLORDON, A.; SOLIS, J.; LABONDE, D.; CLARK, C. Development of a prototype bayesian network model representing the relationship between fresh market yield and some agroclimatic variables known to influence storage root initiation in sweet potato. HortScience, v.45, p.1167-1177, 2010. 